\title{
Exploration of Teaching Reform of the Ideological and Political Theory Course for Science and Engineering Students-A Case Study on University T
}

\author{
SONG Kaili ${ }^{1}$, YU Jianxing* JI Ying(corresponding author), LIU Zhou ${ }^{2}$, LUO Zhen ${ }^{3}$, ZOU Jiming ${ }^{3}$ \\ School of Education, Tianjin University \\ Tianjin, 300350
}

\begin{abstract}
Ideological and political theory course is an important part of the ideological communication of the party and the state, and undertakes the important mission of arming with theories, value guidance and talent cultivation. As an important research university in science and engineering in China, university $T$ has always attached great importance to the ideological problem in the process of talent training. In the education teaching mainly for science and engineering students, it tries to explore the teaching mode which is suitable for the students of science and engineering and have the intersecting characteristics of the liberal arts and science, so as to cultivate the innovative talents with political quality. Through the case analyzing of the teaching reform of the ideological and political theory course, it hopes to bring some supplementary and enlightening content to the relevant research.
\end{abstract}

Keywords-Science and engineering; Ideological and political theory course; Teaching reform

\section{INTRODUCTION}

The ideological and political theory course in colleges and universities is a systematic project that shapes souls, and the teaching reform thereof is shouldered with the important mission of arming with theories, value guidance and talent cultivation. Relatively speaking, the humanistic foundation of science and engineering undergraduates is weak and their burden of homework is heavy; moreover, they are influenced by inherent thinking pattern and certain learning habits. Those together result in difficulties and uniqueness in ideological and political theory teaching for science and engineering students. Therefore, the corresponding exploration on its teaching reform is of theoretical and practical significance. University $\mathrm{T}$, as a domestic key research university of science and engineering, plays a leading role in the teaching reform exploration. It always attaches great importance to ideological issues in talent cultivation, and promotes the ideological and political theory teaching reform in an orderly manner by forming and fully implementing systematic teaching reform programs.

\section{MAIN PROBLEMS IN IDEOLOGICAL AND POLITICAL THEORY TEACHING FOR SCIENCE AND ENGINEERING STUDENTS}

\section{A. Lack of participation of teaching subjects}

As the learning content of science and engineering students tends to be more practical, the students value practice more and have not paid enough attention to ideological and political theory course. Moreover, the students learn with a strong purpose and utilitarian nature. For example, the students usually try to gain access to the party and obtain high scores without actual agreeing with, accepting and internalizing these theoretical ideas. In addition, since there is a tendency of "focusing on research instead of teaching" in research-oriented universities, the investment paid in the teaching of ideological and political theory course, which is a public course, is relatively small. As overloaded with their own burden and pressure of research, teachers has few energy and motivation for the teaching reform, and their enthusiasm for participation in teaching reform is low, resulting in the fact that the research and teaching of theories has not yet formed as an organic whole.

\section{B. Lack of common discourse system between teachers and students}

In most cases, the teachers of ideological and political theory course working in science and engineering universities are of liberal arts majors, and have a relatively monotonous knowledge background. As a result, there are differences in knowledge background and thinking pattern between them and the students as they teach their knowledge of ideological and political theories to science and engineering students. The characteristics and demands of the students are not fully understood, the learning content is not completely delivered and the students' acceptance and sympathetic response level are low. Since the undergraduates come from all over the country, the students' cultural background, ideas and religious beliefs are different. This will inevitably lead to the different demands of students in the ideological and political theory course. However, it is difficult for the current school education to fully meet the different demands of students, so a considerable 
number of students have a certain degree of antipathy on the ideological and political theory teaching.

\section{Lagging of teaching media application}

The diversification and modernization of teaching media make the teaching resources change from a relatively conservative and closed state to an open and shared one, and the teaching mode change from an one-dimensional planar mode to a multi-dimensional stereoscopic mode [1]. For example, the appearance of the "mooc", "micro-course", "flipped course" breaks the limitation of time and space, gives students more learning autonomy and choices, and enhances the teachers' ability to use modern teaching technologies. Science and engineering colleges and universities with a large number of reserve technical personnel for the implementation of on-line ideological and political theory education should give full play to their own advantages and play a leading role. However, the ideological and political theory course for science and engineering students is mainly based on some conventional means currently, and it lags behind in modern technology application and media choosing.

\section{Monotonous course assessment methods}

Although some teachers introduce Q\&A, major assignment and group discussion to their class and take the assessment of the above-mentioned processes into students' final scores counting, they still take up a relatively small portion of the total scores counting. The main form of assessment is still based on the final examination, which is scheduled by universities or schools in a unified manner. Limited by teaching time arrangements, the results of the single final examination cannot be fed back to students in a timely manner, and are mainly used in teachers' teaching reflection. This leads to a certain degree of formalism in assessment and wrong learning attitude of students, including the appearance of harmful style of study such as pre-test cramming. These all deviate from the original intention of the ideological and political theory course assessment.

\section{SPECIFIC CONTENT OF THE TEACHING REFORM EXPLORATION OF UNIVERSITY T}

University $\mathrm{T}$ is the first university to set up an ideological and political theory teaching institution led directly by school party committee since the foundation of the nation, and it has established a interdisciplinary teaching and research team of ideological and political theory course. In order to effectively solve the problems of ideological and political theory teaching for science and engineering students and to stimulate teachers and students to participate in the teaching reform of ideological and political theory course, University $\mathrm{T}$ has made unremitting efforts. The school has set up an ideological and political education system with the upper, middle and lower levels collaborating together and a trans-department and open-ended innovative community for the teaching methods of ideological and political theory course; moreover, all-round and stereoscopic teaching reform situation has been created.

\section{A. Overall design of the teaching reform exploration of university $T$}

In the upper level, a leading group for ideological publicity is established. The group is led by the school party leaders, including the deputy secretary of party committee in charge of ideological work and the vice president in charge of teaching. Moreover, departments such as the party committee propaganda department, academic affairs department, school of postgraduate, liberal arts department, personnel department, finance department, student affairs department, etc. participate in the reform. Some offices and an ideological and political theory teaching reform guiding committee are set during the reform.

In the middle level, the advantages of the school system are given full play. In accordance with the requirements of the central authority, fragmentation is avoided, and diversified and interdisciplinary teaching and research teams of ideological and political theory formed by the party leaders, full-time teachers, and student cadres (political counselors, mental-health counselors, and honkers) are established; the tutorial system is implemented in the ideological and political theory course; the three teams are integrated, two types of class are integrated, and education and teaching programs are designed in an organic manner.

In the lower level, political and ideological interdisciplinary seminars for young and middle-aged teachers are held. Interdisciplinary research on the current theoretical hot spots, difficulties and doubts is carried out. As a platform for the normalized communication between teachers and students, the research is carried out through academic luncheon, WeChat, on-line forum dedicated to the communication between teachers and students, etc.

In order to construct a set of reproducible and scalable ideological and political theory course teaching reform systems and modes, university $\mathrm{T}$ follows the idea of pilot before popularization, conducts pilot reform in department Q, summarizes experiences and lessons, adjusts and optimizes resource allocation, and popularizes it to other faculties or schools.

\section{B. Pilot reform practice of department $Q$}

1) Optimizing the teaching content of ideological and political theory course

View of nature, view of science and technology and technological innovation methodology and some other content in the postgraduate students' public ideological and political theory course "dialectics of nature" are moved to the department Q's ideological and political theory course for undergraduates, so as to help students establish and master the Marxist world view and methodology, solve the students' problems in thinking and further solve their problems in political stand. The advanced information of this course, some current events and hot spots are included into the curriculum content system, and dialectical thinking and innovative thinking are exposed to and understood by some advanced undergraduate students ahead of time. These enhance students' interest in learning the theoretical knowledge of natural sciences and social sciences. 


\section{2) Flexible and diverse teaching organization}

For example, teaching by a group of teachers is adopted in the "ideological and moral cultivation and legal basis", "basic principle of Marxism" and some other courses, wherein one specialized teacher teaches as the chief of the course while the course is divided into a number of topics which are taught by other teachers in the group. This method has changed the previous situation of solitary struggle, and the teaching tasks are shared by many teachers. The background knowledge of different disciplines is integrated, which gives students a fresh learning experience, and motivates both sides' enthusiasm to some extent.

\section{3) Diversification of teaching ways and methods}

Department Q includes thematic reports, psychological drama, speech, debate, etc. into the teaching of ideological and political theory. A wide range of teaching methods give the students the opportunity to fully demonstrate and exercise their ability, and make the students find their own fun and sense of achievement in their independent exploration. These enhance students 'ability to learn independently as well as their team spirit, and stimulate students' motivation to learn to some extent. For example, in the course of "innovative thinking and science and technology entrepreneurship", experts from enterprises and institutions are invited to give lectures on specific topics of the course; in the course of "ideological and moral cultivation and law basics", experts of law are invited to give lectures and students are required to form a group so as to demonstrate their assignment in the form of a stage show. The former president of Tianjin Polytechnic University was invited in this semester to make speech on "growth and development", and professors of Nankai University was invited to interpret the spirit of the 19th NPC report.

\section{4) Reform on course assessment mode}

"Comprehensive assessment" mode is adopted. The socalled "comprehensive assessment" mode refers to changing from the past single closed-book examination at the end of the year to a variety of assessment methods based on the nature of the course and changing from knowledge-based assessment to ability-based assessment which emphasizes more on process evaluation [2]. For ideological and political theory course, the main purpose is not to assess but to enable the learners to accept certain values and specific theoretical methods. Such education of the emotional values requires to integrate the assessment into the whole learning process and individual life perception, which needs to evaluate the acceptance of students and their individual thoughts. Therefore, assessment methods such as reading report, essay writing and practical investigation shall be adopted instead of a single closed-book examination for theoretical knowledge. For example, the class performance, participation in interaction, high-level speech in discussion part, essay writing, extracurricular practice and other aspects of the assessment shall be included in the usual performance, and the proportion of usual performance in the total scores shall be raised. Moreover, open-book examination and oral examination can be adopted for some content according to needs.

\section{5) Taking the fulfillment of students' needs as a fundamental}

According to the science and engineering students' learning characteristics and preferences, theories and practice are closely linked together. For example, a series of specialized courses entitled "innovative thinking and science and technology entrepreneurship" have been launched, and the specific theories from "dialectics of nature" are applied to student entrepreneurship guidance. Moreover, with the help of new media, timely attention to various issues and effective assistance are given to students faced with various problems, so as to promote mutual understanding between teachers and students. At present, the course of "basic principles of Marxism" is taught with flipped class, wherein the media favored by students, such as micro-blog and WeChat, are combined with the traditional teaching methods of ideological and political theory education and micro-technology, microculture and micro-activities are carried out actively. On-line learning is problem-oriented, while off-line learning is Q\&Aoriented and discussion-oriented. To a certain extent, these measures have promoted students' interest and participation in learning.

\section{Achievements of the ideological and political theory teaching reform of department $Q$}

The teaching reform in the ideological and political theory course is a systematic project which cannot be done in a single step and requires a long period of exploration and practice. At present, university $\mathrm{T}$ has conducted teaching reform in a number of ideological and political theory courses for students enrolled in 2015, 2016 and 2017 in department Q, benefiting more than 600 undergraduates and gaining a good response from teachers and students. The passive cramming is gradually changed into active participatory learning, and students learn and apply the theoretical knowledge in a creative manner; moreover, they actively joined the competition for ideological and political theory demonstration course of 2016 for university students in Tianjin. Participated in the second innovative methods application contest of 2016 for university students in Tianjin for the first time, they have won a second prize and three third prizes.

\section{MAIN CHARACTERISTICS OF THE TEACHING REFORM EXPLORATION OF IDEOLOGICAL AND POLITICAL THEORY COURSE IN UNIVERSITY T}

\section{A. Establishing professional teaching team to promote teaching reform}

The leading teacher is the chief responsible person of the course group as well as a renowned teaching master; the teaching assistant team is a group consists of personnel of student affairs department, counselors and postgraduates from school of Marxism, and they focus on on-line teaching and practical teaching so as to ease the burden of the leading teacher; the team of specially-invited experts for particular topics is composed of scholars with great achievements, leaders of Tianjin and the school as well as outstanding alumni. Such a diversified teaching team breaks the teacher's solitary struggle in traditional teaching and enhances the collision and 
integration in thinking among different disciplines. At the same time, it also eases teachers' teaching burden and helps to exert collective wisdom and team strength to the maximum.

\section{B. Fully respecting the student's dominant position}

For example, personalized training programs are designed for individual students, and a classified and stratified training mode is adopted. Students who aspire to grow into political leaders are given more learning opportunities and platform for growth. In the course "ideological and moral cultivation and legal basis", situational teaching is applied into the ideological and political theory teaching process, allowing students to choose their own themes, make groups spontaneously, and create stage show independently, so as to stimulate students' interest in learning. The students' emotional experience is concerned, their subjective status and participation are highlighted, and their actual demands are fulfilled.

\section{Establishing a teaching discourse system with characteristics of nature science}

According to the characteristics of science and engineering students and their development needs, department $\mathrm{Q}$ pilots classified teaching in its ideological and political theory course. It comprehensively analyses the relationship among modern science, Chinese excellent traditional culture and Marxism, and socialism with Chinese characteristics and Chinese outstanding traditional culture and Marxism as well as the relationship between socialism with Chinese characteristics and the Chinese outstanding traditional culture heritage and innovation. Through the integration of theories, ideas, concepts and principles of modern science and Chinese outstanding traditional culture, a new teaching discourse system with characteristics of nature science is constructed, and students' acceptance of the ideological and political theory course is enhanced.

\section{Creating a new teaching mode with new media}

The new media favored by students are adopted to carry out teaching, which conforms with the modern characteristics and development direction of the ideological and political theory education. University $\mathrm{T}$ makes full use of its own resources, establishes a collection of teaching cases and the database of ideological and political theory course, and creates a new teaching mode featuring off-line, on-line, intra-curricular, extracurricular and practice, providing information services for the majority of teachers and students.
V. REFLECTION ON THE IDEOLOGICAL AND POLITICAL THEORY TEACHING REFORM FOR SCIENCE AND ENGINEERING STUDENTS

\section{A. Taking the fulfillment of the students' spiritual needs as a logical starting point}

The essence of the ideological and political theory teaching in colleges and universities is that the students should sincerely accept and agree with the ideology advocated by the party and state, internalize the scientific world view and methodology of Marxism and creatively make use of these knowledge to analyze and solve the various problems encountered in real life. Such soul shaping project should aim at enhancing the spiritual taste of science and engineering students, enriching their spiritual world, shaping independent personality traits and perfecting their moral and ethical sentiments.

\section{B. Establishing a more diversified teaching and research team}

The results of teaching reform depend on the quality of the teaching staff in most cases. Most teachers in schools adept in science and engineering have an educational background in science and engineering, and the same teacher usually teaches the same course over a long period of time. This is harmful to the overall quality improvement of the teachers and the learning experience and effectiveness of the students. A diversified teaching and research team is established, and various teaching parts are redesigned, which not only helps the mixture and integration of different disciplines, but also distinguishes outstanding teachers from the crowd, providing solid foundation for the sustainable development of the ideological and political theory teaching reform. Therefore, a reasonable echelon structure of teaching team has become the development trend of the ideological and political theory teaching reform in the future.

\section{Adopting modernized and comprehensive teaching methods}

With the rapid economic and social development in our country, the traditional cramming teaching methods and modes, which are mainly characterized by knowledge infusion, cannot meet the teaching demands of modern ideological and political theory course. As the information technologies are highly developed nowadays, modern educational technology means are popular, and combining multimedia, Internet and other advanced technologies with the traditional teaching methods to strengthen curriculum resources construction has become the new trend [3]. In addition to learning in class, more abundant, flexible and convenient resource exchange and sharing platforms shall be created for students, so as to cultivate students' awareness and ability of independent learning and to meet the students' personalized development demands. 


\section{CONCLUSION}

Teaching reform is not a mono-drama, but a result driving by the both side. Without students' studying, teachers' teaching makes no sense. The teaching reform exploration made by university $\mathrm{T}$ fully respects the both sides; the existing teaching resources are integrated on the premise of implementing upperlevel arrangement, providing a strong resource guarantee and a broad learning platform for the reformers and reform undertakers and stimulating enthusiasm for the reform members. The specific learning content and teaching methods are chosen based on the learning characteristics of science and engineering students. According to the actual demands of students, a diversified curriculum system is implemented and appropriate new media are selected as the teaching carrier, so as to encourage students to give full play to their own subjectivity and to actively participate in the teaching reform.

For the teaching assessment, more emphasis is placed on the use of process evaluation. Instead of score gaining, the acceptance and satisfaction of students as well as the timely feedback on the learning effect are set as the main basis for teaching assessment, which conforms to the development trend of the modern educational evaluation theory. These measures enhance the persuasiveness, inspiration, pertinence and effectiveness of the ideological and political education and teaching, so that the undergraduates of science and engineering would agree more with these theories and truly internalize and apply what they have learned and obtained.

\section{ACKNOWLEDGMENT}

SONG Kaili (1992-), female, master from College of Education, Tianjin University, mainly engaged in research of higher education (first author)

YU Jianxing (1958-), male, doctor, chief scientist of national "937 program" and professor from School of Architectural Engineering, Tianjin University, mainly engaged in research of ocean resource development and management and study of higher education (manager of the funded project, corresponding author)

LIU Zhou (1971- ), male, doctor and associate professor from College of Marxism, Tianjin University, mainly engaged in research of philosophy of science and technology

JI Ying (1984- ), female, master, research assistant and secretary of vice section level from truth seeking department, Tianjin University, mainly engaged in management of higher education. ( corresponding author)

LUO Zhen (1967- ), male, doctor, professor and deputy director of truth seeking department, Tianjin University, mainly engaged in management of higher education

Zou Jiming (1961- ), male, bachelor, associate researcher and party secretary from College of Literature, Tianjin University, mainly engaged in research of ideological and political education

[Funded project] "world-oriented, future-oriented and engineering-oriented" research and practice on the training mode of new engineering talents, a key project on teaching quality and teaching reform research for undergraduate talents implemented in Tianjin in the year of 2017 (Number: 171005601B).

\section{REFERENCES}

[1] LAI Xuemei, Li Jian. Evolution of teaching reform of ideological and political theories in colleges and universities from the perspective of new media [J]. School Party Building and Ideological Education, 2016 (07):67-70.

[2] ZHANG Fuzhen. Exploration of theoretical course assessment in ideology and politics_creating compound course testing system [J].Intellect, 2015 (01):96-97.

[3] GUO Fengzhi. Research on the reform of teaching methods of ideological and political theory course in colleges and universities under the conception of modern education[J]. Leading Journal of Ideological \& Theoretical Education, 2013 (10):71-75 